\title{
Provocative and rewarding genetics
}

William J. Schull

Genetics, Evolution and Man. By W. F. Bodmer and L. L. Cavalli-Sforza. Pp. xv+782. (Freeman: San Francisco, 1976.) $\$ 13.95$.

Frve years ago, these authors gave us The Genetics of Human Populations (1971), a book addressed more to the specialist or advanced student than the neophyte. Genetics, Evolution and Man projects the notions set forth in this earlier effort on to a wider, less specialised readership. Their newer book expands the admirable features of its predecessor-excellent illustrations, conceptually and graphically; succinct abstracts at the beginning of each chapter, providing a sense of direction for the reader; the intercalation of frequent one-or two-line statements which capture the essence of the paragraphs which follow; problems which test and supplement one's understanding of each chapter; and a lucid, readily readable literary style. More important, perhaps, is its currency and the overall objectivity which Bodmer and Cavalli-Sforza bring to the task which they set for themselves. This does not imply that every human biologist will subscribe fully to their arguments on controversial issues-for example, the roles of heredity and environment in the observed differences among the races in tests of intelligence. Even where honest differences of opinion exist, however, it should be clear to all save the most committed that they make a serious appeal to reason rather than exhibit a preconception or prejudice.

This is unquestionably an important book, and everyone familiar with the subject matter must appreciate the wealth of information to which the uninitiated reader is exposed. It is provocative, but not provoking; it rewards without remonstrating. Each reader, indeed each reviewer, will undoubtedly be attracted to a different chapter. One of my favourites is the "Evolutionary Development of Modern Man". It attempts a synthesis of man's biological and social evolution as a human population geneticist might see it. The observations on which this synthesis is based are, of course, sensitive to substantial differences of interpretation both as to time and significance. Illustrative of such differences are the re- ferences to the Jomon culture of Japan. Development of pottery by this culture is cited to be $9,000 \mathrm{yr}$ ago, but Japan; Its Land, People and Culture (UNESCO 1958) suggests this event actually occurred about 14,000 yr ago; whereas the 'carliest Jomon' is given by Komatsu (The Japanese People, 1962) as about 6,400 yr ago. Apparently, Bodmer and Cavalli base their estimate on the carbon dating, carried out at the University of Michigan some years ago, of charred wood recovered from the Natsushima shell-mound in Kanagawa Prefecture. This specific example is not particularly important and quite possibly the figure given by Bodmer and Cavalli may be correct, but some of the 'facts' of their general argument will undoubtedly prove to be in error. This, however, is a much lesser moment than the synthesis and its respect for the divergent data sets which must, in some manner, be integrated. Their view does not disregard man's cultural evolution nor does it consciously serve the biological sciences. They acknowledge man's biological and cultural heritage; and seek a quantitative appraisal of the contributions of these elements to his present diversity, not a capitulation on the part of one or the other disciplinary views.

If fault one must find, then this book is overly long. This stems, I believe, first, from a misdirected effort to make the book self-contained-that is, to provide the reader with every detail necessary to understand some of the subsequent arguments; and second, a failure to realise the frequency with which most students are exposed to the structure of DNA, the mechanics of mitosis, and elementary notions of statistics. This is not to suggest that reinforcement is not needed for some -possibly a large number-but a general application of repetition can just as readily lead to boredom as understanding. This is a small caveat, and doesn't seriously compromise the book's general excellence.

William Schull is Director of the Center for Demographic and Population Genetics at the University of Texas Health Science Center, Houston, Texas.

\section{Introduction to methods of geophysics}

Geophysical Methods in Geology. (Methods in Geochemistry and Geophysics, Voil. 12.) By P. V. Sharma. Pp. $\mathrm{xv}+428$. (Elsevier Scientific: Amsterdam, Oxford and New York, 1976.) Dfl. 65; \$26.25.

HERE is a book that attempts to cover the techniques used in the whole field of geophysical research on the crust and lithosphere, industrial and academic; that is, a book that combines the contents of books such as Parasnis (1972), Bott (1971), York and Farquhar (1972) and Cox (ed. 1973). There are chapters on seismic methods (with sections on fundamentals of seismic wave propagation, seismic seismicity and seismotectonics, seismic prospecting, use of surface waves in crustal studies), gravity methods, magnetic methods (from Wenner spreads to magnetotellurics), radiometric methods (dating and prospecting), geothermal methods and, finally, geophysics applied to global tectonics. The book is polymath, up-to-date and non-mathematical; SI units are used and a point in its favour is that most subsections end with a reference to a recent review article. It is a long book but not a verbose one.

Dr Sharma writes that the book developed from a course organised at the University of Copenhagen. "The course was aimed at providing a concise but fairly comprehensive introduction to the methods of geophysics within which the undergraduate students of geology and geophysics could locate their specific interests for further specialisation." $\mathrm{He}$ does not tell us in which year of their undergraduate career these students received this course. No man could have a lively research aquaintance with one half of the subiects touched on here so that the course fand the book) must have represented a con- 